\title{
27
}

\section{Hypertension and Malnutrition as Health Outcomes Related to Ecosystem Services}

\section{Ali Ahmed, Mahin Al Nahian, Craig W. Hutton, and Attila N. Lázár}

\subsection{Introduction}

This chapter explores the well-being of the coastal population of Bangladesh in relation to their ecosystem services, livelihoods, food consumption and health. This is achieved by exploring the specific nature of the association between human health and well-being with the provision of nutrition
A. Ahmed $(\nabla) \bullet$ M. Al Nahian
Climate Change and Health, International Center for Diarrheal Disease Research, Bangladesh (icddr,b), Dhaka, Bangladesh
C. W. Hutton
Geodata Institute, Geography and Environment, University of Southampton, Southampton, UK

\section{A. N. Lázár}

Faculty of Engineering and the Environment and Tyndall Centre for Climate Change Research, University of Southampton, Southampton, UK 
and food diversity by disaggregating elements of this relationship within the seven social-ecological systems (SESs) (see Chap. 22). The specific socio-economic and ecological service components of each SES are identified using data from the sampled household surveys (see, Chap. 23).

Human health and well-being status is closely linked with local ecosystem (see Chap. 7 and MEA 2003). However, the causal relation is complex and often hard to define as they are indirect, displaced in space and time and dependent on a number of modifying forces (Corvalan et al. 2005). The human-ecosystem interaction and how this interaction impacts health is yet to be properly understood or consequently used in policy level decision-making processes.

This work demonstrates how economic conditions, educational levels, environmental conditions and dietary intake differ across SESs and, in turn, is associated with differing health status. A key area of research is the impact of saline water intrusion across the SESs which has critical implications for health, with significant positive associations between hypertension and salinity in drinking water and dietary impact on under-five malnutrition.

\subsection{Methods}

The analysis in this chapter is based on the primary data collected from three cross-sectional household surveys, as described in Chap. 23. Drinking water samples, anthropometry and blood pressure data are collected from household survey participants. Water samples from primary drinking water sources (except bottled and rain water) are tested with a HACH sensION5 electric conductivity metre and blood pressure measured with a OMRON M2 blood pressure monitor. Measurements of individual height and weight were collected from one eligible male (18-54 years), one female (15-49 years) and the oldest under-five child in the family. Blood pressure is collected for male and female respondents only from the 15-59 age group according to selection criteria based on kinship. Standard definitions of malnutrition and hypertension are used in the study:

- Malnutrition: Malnutrition is a condition which results when a person's diet fails to provide adequate nutrients for growth and maintenance or when a physical condition cannot utilise the food consumed due to illness. 
Malnutrition is observed as deficiencies such as thinness, stunting and micronutrient deficiencies, but also as overweight and obesity, known as overnutrition (UNICEF 2012). Under-five child malnutrition is assessed using the World Health Organization (WHO) child growth standard (Z-score) (WHO 2007). Adult health status is assessed using adult body mass index (BMI) category suggested for the Asian communities (Barba et al. 2004).

- Hypertension: Respondent's blood pressure is generated using the average value of last two readings of systolic and diastolic blood pressure. Thresholds for 'normal' are (i) systolic blood pressure (SBP) under $120 \mathrm{mmHg}$ and (ii) the diastolic blood pressure (DBP) under $80 \mathrm{mmHg}$ suggested by the American Heart Association (AHA 2016) and followed in national surveys (NIPORT et al. 2013).

Descriptive statistics are used to show the household characteristics and socio-demographic status of the study area. Health is assessed in terms of under-five child malnutrition and adult health status outcomes by prevalence of underweight, obesity and hypertension. Overall analysis considers explanatory variables of age, sex, educational status, wealth quintiles, seasons, structure of dwellings, occupation, dietary intake, landownership and salinity level in drinking water, and these are mapped across the different SESs. In all the graphs in this chapter, the SESs are listed in order according to the mean raw score of wealth index (poorest (left) to relatively less poor (right) ${ }^{1}$ ).

\subsection{Results and Discussion}

Malnutrition and hypertension prevalence was explored for the southcentral and south-west coastal Bangladesh. Bivariate analysis is used to map the association between SESs for both under-five child malnutrition and adult malnutrition and hypertension.

\subsubsection{Under-Five Child Malnutrition}

To assess the malnutrition of under-five children, three main indices are used: (i) height-for-age (stunting), (ii) weight-for-height (wasting) and (iii) weight-for-age (underweight). In Bangladesh, the prevalence of stunting, 


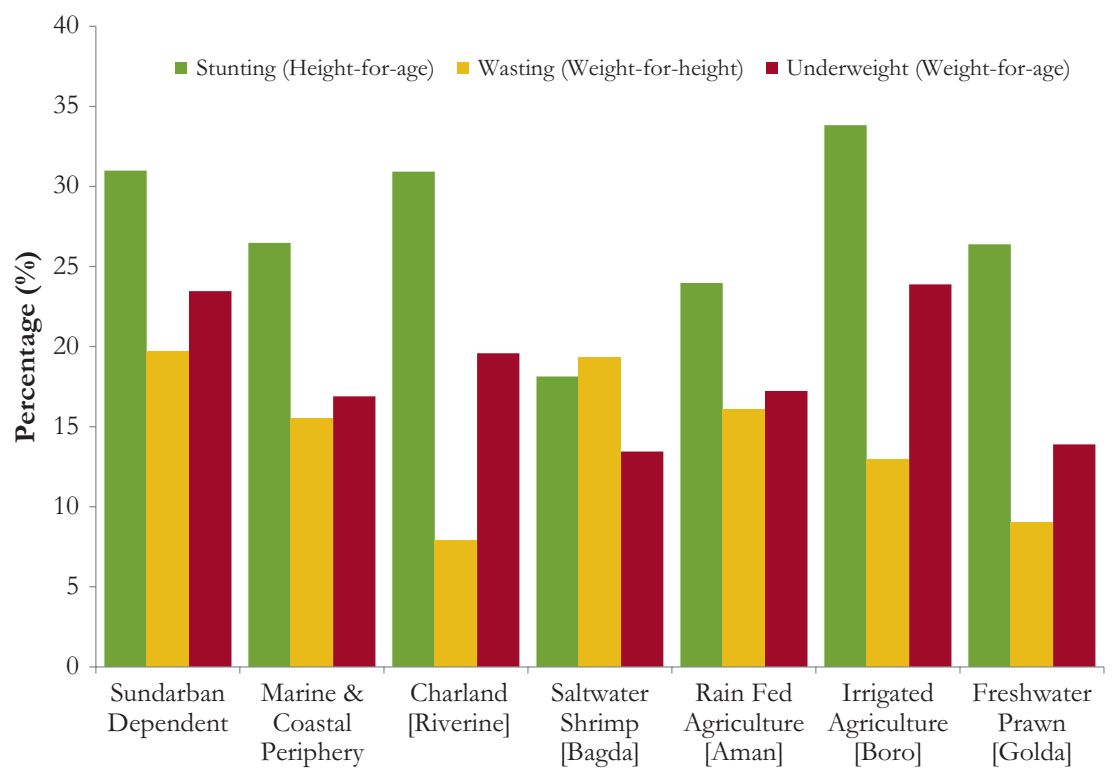

Social-Ecological System

Fig. 27.1 Under-five children malnutrition status by social-ecological system. The SESs are organised left to right order of mean raw score of wealth index (left: poorest to right: relatively least poor)

wasting and underweight for under-five children is roughly 36,14 and 33 per cent, respectively (NIPORT et al. 2016).

Figure 27.1 shows the under-five child malnutrition status in the SESs. In the study area, the percentage of stunting, wasting and underweight is about 28, 14 and 19, respectively, which is comparable to the national findings. With some noticeable exceptions, there is a weak trend of a decline in all three malnutrition indicators across the SESs as relative wealth increases (i.e. highest in the poorest Sundarbans SES to lowest in the relatively better-off freshwater prawn SES), a trend which may be linked to both access to food diversity including fish, which is discussed in relation to Figs. 27.3 and 27.4 .

There are some differences in per capita calorie and protein intake (calculated at household level for all adult and child respondents) among the SESs (Fig. 27.2). The lowest per capita calorie intake is found in Charland 




Social-Ecological System

Fig. 27.2 Per capita mean calorie and protein intake per day across the seven social-ecological systems within the delta region

SES and the lowest protein intake in the irrigated agriculture SES. The highest calorie and protein intake is found in the freshwater prawn (Galda) SES which supports the comparatively high welfare status of this particular SES.

By investigating the diet patterns within the data, fish consumption might be considered one of the key elements particularly in regards to child malnutrition. Fish consumption and under-five child malnutrition status are found to be inversely associated, with some minor exceptions (Fig. 27.3). Among the total protein source, the proportion of fish consumption is lower among poorer households which consequently suffer more from under-five child malnourishment. The higher the fish consumption with diet, the lower the under-five child malnutrition, suggesting fish provide an important safety net for the poorest households against child malnutrition. The analysis also shows (not plotted) that households consuming domestically produced food and vegetable from homestead gardening have lower likeli- 


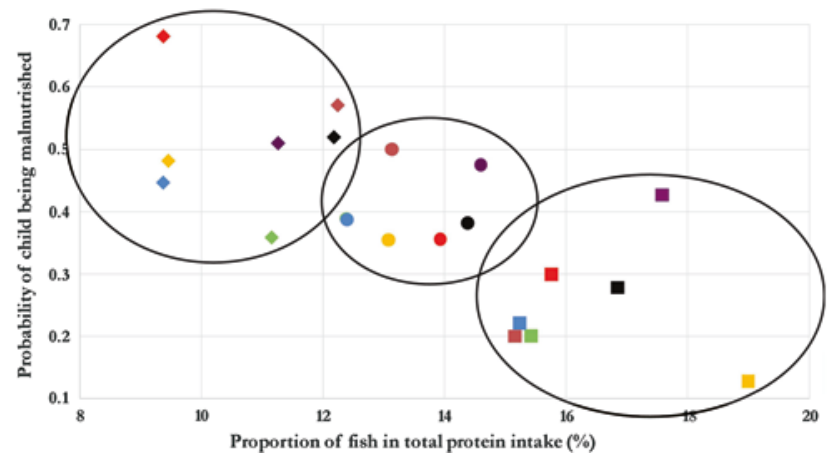

Charland (Riverine)

Sunderbans Dependant Marine and Coastal Periphery

Irrigated Agriculture

Rain-fed Agriculture

Saltwater Shrimp (Bagda)

Freshwater Prawn (Golda)

Fig. 27.3 Association between calorie intake, food diversity and under-five child malnutrition by social-ecological system and poverty level

hoods of child malnutrition than households that mainly purchase the food items. Overall findings suggest that, along with poverty, access to nutrition through total dietary diversity is influencing the under-five child malnutrition in the coastal areas. However, model simulations (see Chap. 25) indicate that the total availability of the fish in the Bay of Bengal is likely to decrease under all projected scenarios. This will negatively impact food intake and dietary diversity and may lead to an increase in the prevalence of child malnutrition in coastal Bangladesh (Fernandes et al. 2016).

In this research, food diversity and calorific intake are found to be positively associated for children under five, and the minimum calorie threshold to substantially reduce under-five child malnutrition is $2000 \mathrm{kcal} /$ person/day (Fig. 27.4). Increased calorie intake and food diversity are, in turn, associated with reduced poverty. Figures 27.3 and 27.4 show that, within each SES, the prevalence of under-five child malnutrition increases with the level of poverty, meaning highest malnutrition was prevalent in the lowest wealth quintile or among the poorest group. Both the food diversity index and protein and calorific value is high in the least poor wealth quintile as is the lower probability of child being malnourished; the opposite picture is visible among the poorest wealth quintile. 


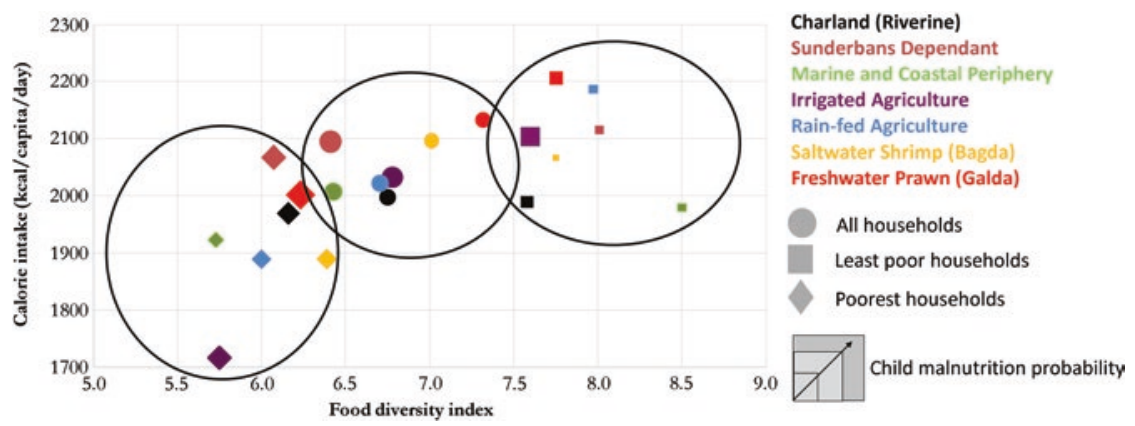

Fig. 27.4 The association between calorie intake, food diversity and under-5 child malnutrition. A marked decline in likelihood of malnutrition is identified at a food diversity index (number of types) of between 6 and 7

\subsubsection{Adult Underweight, Overweight and Obesity}

BMI is a critical indicator to understand adult nutritional status (Bailey and Ferro-Luzzi 1995). The household survey measured the anthropometry of males aged 18-54 years and females 15-49 years. To understand adult nutritional status, the standard measure, body mass index (BMI), is used to estimate the proportion of adults who are underweight, normal range, overweight or obese according to the health risk categories suggested for Asian communities by Barba et al. (2004): (i) underweight, BMI $<18.5 \mathrm{~kg} / \mathrm{m}^{2}$ (thin or underweight); (ii) normal range, $18.5 \mathrm{~kg} / \mathrm{m}^{2} \leq \mathrm{BMI}<23 \mathrm{~kg} / \mathrm{m}^{2}$ (increasing but acceptable risk); (iii) overweight, $23 \mathrm{~kg} / \mathrm{m}^{2} \leq \mathrm{BMI}<27.5 \mathrm{~kg} / \mathrm{m}^{2}$ (increased risk) and (iv) obese, BMI $\geq 27.5 \mathrm{~kg} / \mathrm{m}^{2}$ (higher risk). Health risks include the occurrence of hypertension, diabetes and cardiovascular disease.

Mean BMI was recently found to be $21.5 \mathrm{~kg} / \mathrm{m}^{2}$ in the coastal population which is slightly below than national average of $22.3 \mathrm{~kg} / \mathrm{m}^{2}$ (NIPORT et al. 2016). Among those surveyed in the study area, for those below the 50 per cent wealth quintile, the mean BMI was found to be $20.7 \mathrm{~kg} / \mathrm{m}^{2}$, 


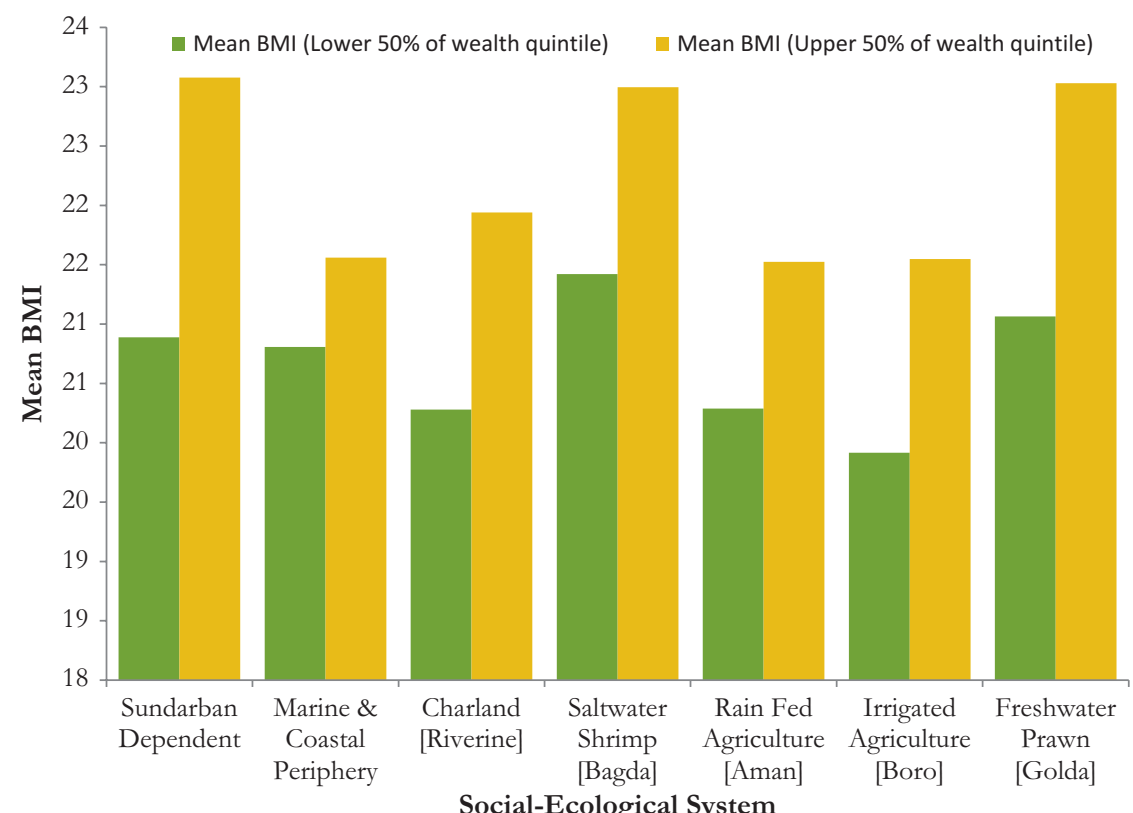

Fig. 27.5 Mean body mass index by wealth quintiles within the social-ecological systems

and for those above this wealth level the BMI reflects the national average. From Fig. 27.5, it is clear that this wealth differential in BMI is also reflected at SES level, a higher mean BMI indicating that the wealthier are more at risk of health issues than those of a poorer wealth status.

Calorie consumption has a direct impact on health and may reasonably be expected to be influenced by poverty and the broader socioeconomic status of the community. Generally, the better-off economic situations should relate to good adult nutritional status, but this is not observed in this study. Age and sex disaggregated results (Figs. 27.6 and 27.7) clearly show that adult malnutrition is higher in women for all age groups and in all SESs (except for under 35s in the brackish shrimp (Bagda) areas), which may be linked to the established phenomenon of women missing meals to ensure food for other household members or only taking food at the end of a meal. However, women are also considerably more likely than men to be overweight or obese. 


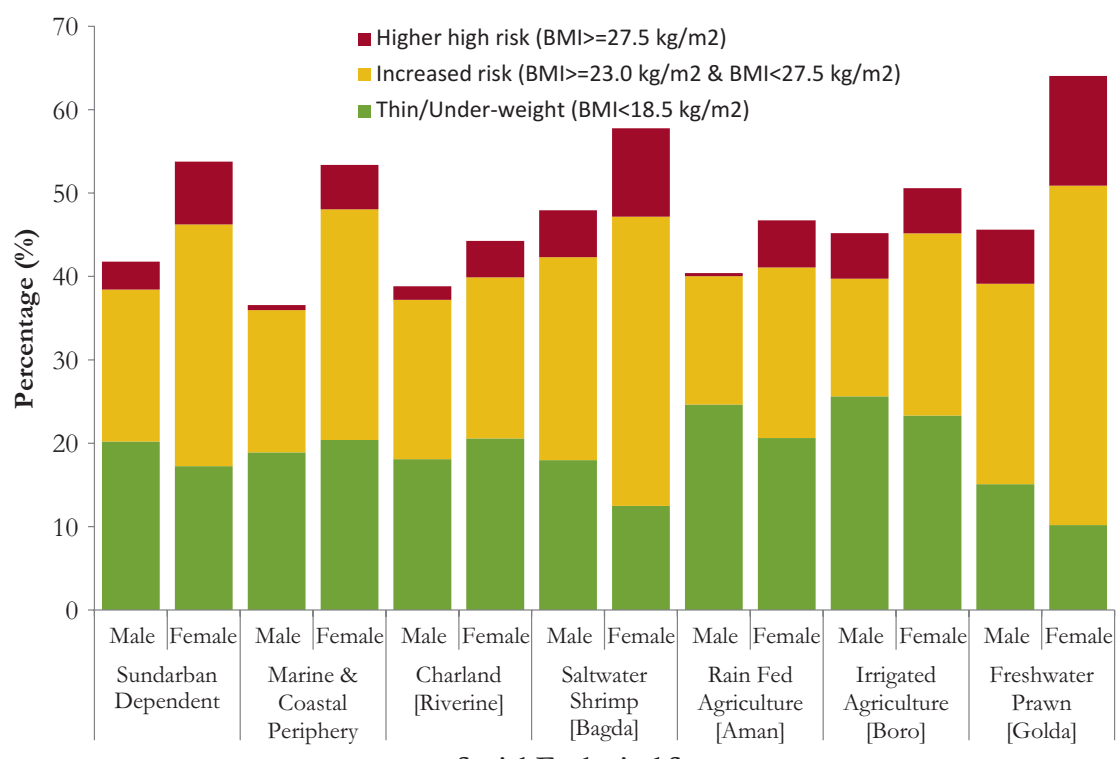

Social-Ecological System

Fig. 27.6 Percentage of adults within each body mass index category by socialecological system and sex

The overall adult malnutrition (by age and sex) is highest in freshwater prawn (Golda), brackish shrimp (Bagda) and Sundarban-dependent SESs (Figs. 27.6 and 27.7).

Coastal population from both aquaculture SESs is at higher risk of malnutrition due to overweight and obesity, whereas people in the agriculture SESs are more at risk of being underweight. Along with poverty incidence and dietary intake, local livelihood pattern might have some significant impact on adult nutritional status. However, this will require further investigation to properly understand within the context of the ecosystem-based SES framework.

\subsubsection{Adult Hypertension}

The World Health Organisation (WHO) identifies hypertension as one of the most important causes of premature death worldwide (WHF 2017). Hypertension is diagnosed through blood pressure measurements. 


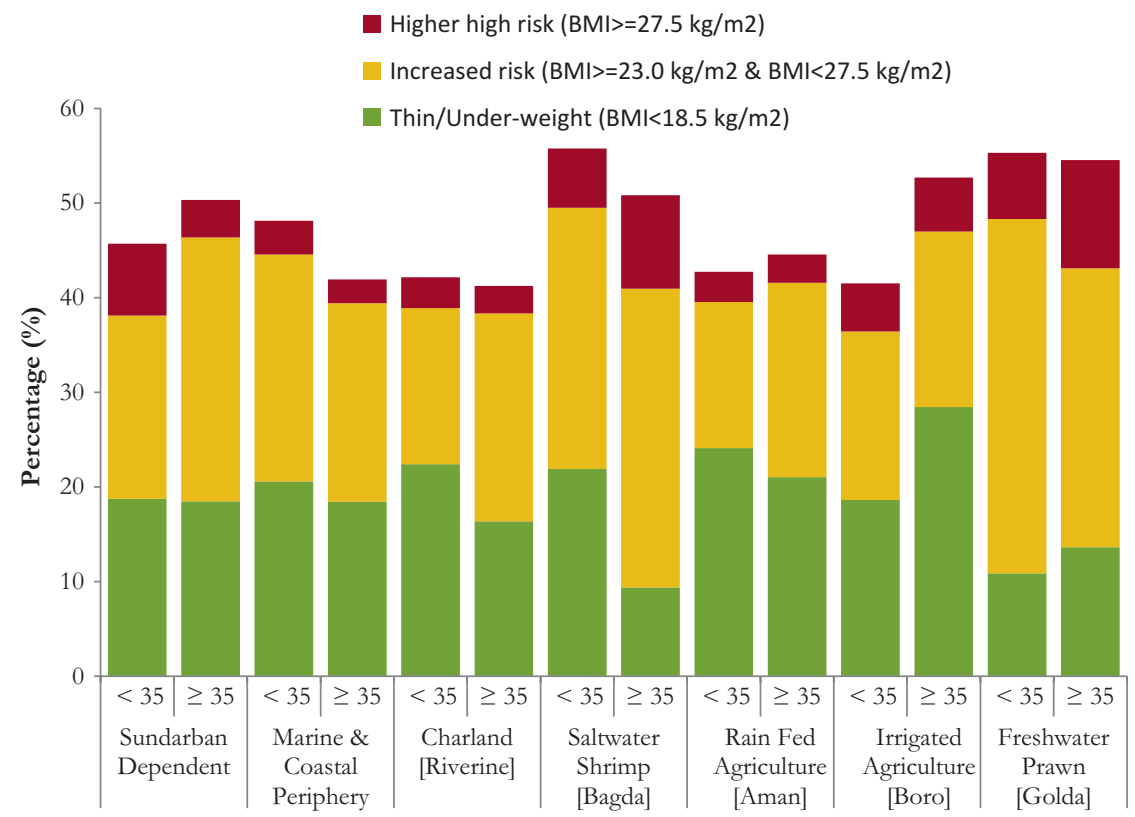

Social-Economic System

Fig. 27.7 Percentage of adults within each body mass index category by socialecological system and age

During the household survey, blood pressure of one eligible male and female was collected, and the average value of last two readings from the three readings of SBP and DBP was used to report respondent's blood pressure as well as to maintain comparability with national statistics (NIPORT et al. 2013). The American Heart Association's definition was used for classifying blood pressure: (i) normal (systolic blood pressure $<120 \mathrm{mmHg}$ and diastolic blood pressure $<80 \mathrm{mmHg}$ ), (ii) prehypertensive (systolic blood pressure 120-139 $\mathrm{mmHg}$ or diastolic blood pressure $80-89 \mathrm{mmHg}$ ) and (iii) hypertensive (systolic blood pressure $\geq 140 \mathrm{mmHg}$ or diastolic blood pressure $\geq 90 \mathrm{mmHg}$ ) (AHA 2016).

Increased blood pressure associated with drinking water salinity has become an immerging public health concern in different parts of the world (Khan et al. 2014; Talukder et al. 2016). This is a concern in coastal Bangladesh, as about 80 per cent of coastal population depends 




Social-Ecological Systems

Fig. 27.8 Comparison of per capita daily sodium consumption (grammes) from different sources and mean salinity by social-ecological system (dashed line represents the WHO daily intake recommendation)

on groundwater for drinking purpose (Shamsudduha 2013), a critical ecosystem service in this deltaic country.

Sodium intake from a range of sources was collected: drinking water, food and table salt (Fig. 27.8). From the collected data, the average drinking water salinity across the SESs is found to be $854 \mathrm{mg} / \mathrm{l}$ (higher for tube wells where mean salinity is $915 \mathrm{mg} / \mathrm{l}$ ); although mean salinity level is close or higher than the Bangladesh safe drinking water standard of $1000 \mathrm{mg} / \mathrm{l}$ (Ahmed and Rahman 2000) in almost every SESs except Riverine Charland. Furthermore, people's daily per capita sodium intake is much higher than the WHO recommendation (two grammes per capita per day) in coastal Bangladesh (WHO 2012; Rasheed et al. 2014).

For the 35 years and above age group, the gender-specific adult hypertension among the coastal population is shown in Fig. 27.9, compared with national rural statistics (NIPORT et al. 2013). Women are found more 


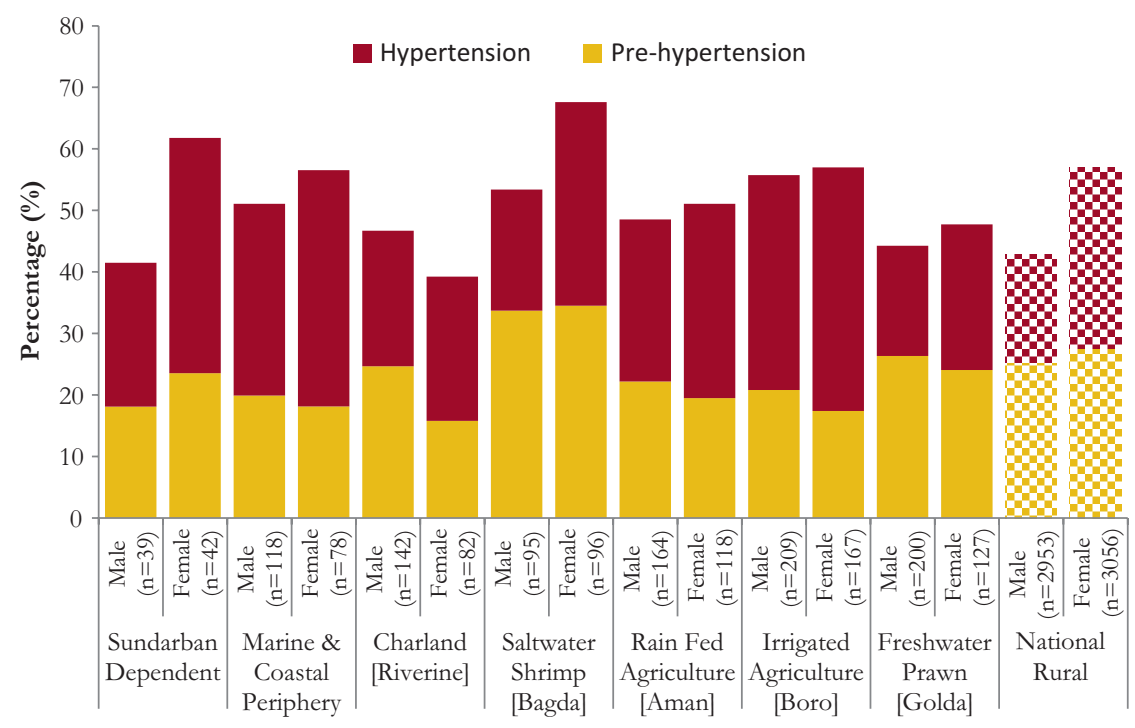

Social-Ecological System

Fig. 27.9 Number and percentage of hypertension and pre-hypertension for males and females 35 and above by social-ecological system (National data from NIPORT et al. 2013)

hypertensive in all SESs compared to men except Charland SES. Both women and men from the irrigated agriculture SES are found to be most hypertensive among the respondents. The prevalence of hypertension is also higher than national rural statistics in most of the SESs for both men and women aged 35 years and above (Fig. 27.9). High blood pressure varies slightly among SESs and about 53 per cent women and 49 per cent male respondents are found to be pre-hypertensive and hypertensive when considering only tube wells as the primary water source.

For further analysis into the association between water salinity, blood pressure and age, drinking water salinity is divided into four categories by source and age into two categories. Firstly, sources of groundwater (tube well, stand post, public tap, etc.) are grouped under 'tube well' and all surface and other sources as 'non-tube well'. As around 97 per cent of the national population depends on underground sources for drinking water (Shamsudduha 2013), the 'tube-well' category was then further divided using (i) the safe water limit (freshwater $<1000 \mathrm{mg} / \mathrm{l}$ ) following 
the Bangladesh guideline of safe drinking water (Ahmed and Rahman 2000), (ii) slightly saline (1000-2000 mg/l) and (iii) moderate saline $(\geq 2000 \mathrm{mg} / \mathrm{l}$ ); the latter two categories based on expertise and judgement in the absence of an official standard. A high saline category $(\geq 3000 \mathrm{mg} / \mathrm{l})$ was initially created but, due to very limited number of samples, was combined with moderate category. Respondents (only eligible male and female $15-59$, no children) were also divided into two age categories namely 'below 35 (15-34 years, $N=2895$; 46.6 per cent)' and ' 35 and above (35-59 years, $N=3319 ; 53.4$ per cent)' to assess the hypertension prevalence in different age groups and also to compare with previous national studies.

The prevalence of high blood pressure (both pre-hypertension and hypertension) steeply increases with drinking water salinity concentration (Fig. 27.10). The results also indicate that the 35 years and above age group are more susceptible to hypertension than below 35 years age group.

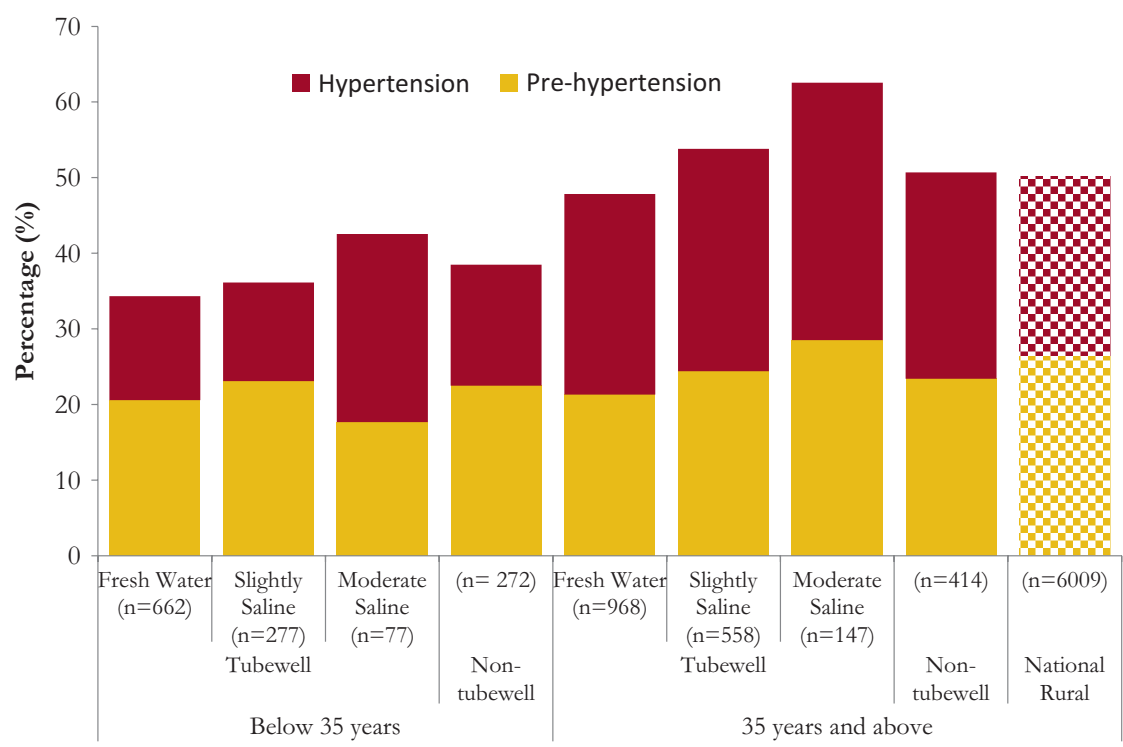

Salinity level

Fig. 27.10 Comparison of drinking water salinity levels with the occurrence of adult pre-hypertension and hypertension. Salinity levels: freshwater $(<1000 \mathrm{mg} / \mathrm{L})$, slightly saline (1000-2000 mg/L), moderately saline (>=2000 mg/L). (National data from NIPORT et al. 2013) 
The prevalence of hypertension is found higher in the coastal areas than the national rural average in all age group (Fig. 27.10), when only tubewell water is considered. Among people who use non-tube-well water sources, in 35 years and above age group, the prevalence of hypertension is higher and pre-hypertension is lower than the national rural average, which means that there may be some other contributing factors such as dietary practice, livelihood and so on.

Future salinity projections for coastal Bangladesh (see Chaps. 17, 18 and 28) indicate a localised increase in groundwater salinity by mid- and end of the century. This is likely to increase the risk of hypertension prevalence in coastal community unless there is proper policy intervention.

\subsection{Conclusion}

Overall, in the coastal area of Bangladesh, under-five child malnutrition is lower in some SESs than the national average. However, to some extent, the simple relationship between poverty and malnutrition is disrupted by access to fish and other diverse food groups. Food diversity, sufficient calorific and fish intake and domestically grown food from homestead gardening and consumption are shown to be beneficial against child malnutrition, with a clear indication that there needs to be between six and seven major food groups within the diet of children before a steep decline in malnutrition is identified.

Fish protein is shown to have a negative association with child malnutrition even where it replaces other sources of protein, thus universal fish consumption could have major benefits in terms of population health. While this is already recognised, this work offers the tangible evidence to support policies and interventions to ensure universal access to, and affordability of, protein sources (see Chap. 2).

In terms of adult malnutrition, women are more vulnerable than men in terms of both being under and overweight. Being overweight or obese is more prevalent in higher wealth quintile group and being underweight in the poorer groups.

Hypertension is higher in the delta region than nationally, even when accounting for age and gender. Though table salt is the highest contributor 
in daily consumption, saline drinking water is another key predictor of adult hypertension. It has been projected that, climate and environmental change will likely exacerbate saline water intrusion into drinking water sources (see Chap. 28). The results here suggest that adaptation interventions and planning for this increased risk could effectively include community sensitisation to salt consumption practices, given the underlying environmental exposure.

Along with poverty incidence, dietary diversity and salinity intake have significant impact on adult nutrition and ultimately on health status, underscoring the direct interaction between the ecosystem services and well-being outcomes.

\section{Note}

1. As calculated using STATA 13.0 (http://www.stata.com/).

\section{References}

AHA. 2016. About high blood pressure. American Heart Association. http:// www.heart.org/HEARTORG/Conditions/HighBloodPressure/ GettheFactsAboutHighBloodPressure/The-Facts-About-High-BloodPressure_UCM_002050_Article.jsp. Accessed 28 Mar 2017.

Ahmed, M.F., and M. Rahman. 2000. Water supply and sanitation: Rural and low income urban communities. Dhaka: ITN-Bangladesh, Center for Water Supply and Waste Management, BUET.

Bailey, K., and A. Ferro-Luzzi. 1995. Use of body mass index of adults in assessing individual and community nutritional status. Bulletin of the World Health Organization 73 (5): 673-680.

Barba, C., T. Cavalli-Sforza, J. Cutter, I. Darnton-Hill, P. Deurenberg, M. Deurenberg-Yap, T. Gill, P. James, G. Ko, A.H. Miu, V. Kosulwat, S. Kumanyika, A. Kurpad, N. Mascie-Taylor, H.K. Moon, C. Nishida, M.I. Noor, K.S. Reddy, E. Rush, J.T. Schultz, J. Seidell, J. Stevens, B. Swinburn, K. Tan, R. Weisell, Z.S. Wu, C.S. Yajnik, N. Yoshiike, P. Zimmet, and W.H.O. Expert Consultation. 2004. Appropriate body-mass index for Asian populations and its implications for policy and intervention strategies. The Lancet 363 (9403): 157-163. 
Corvalan, C., S. Hales, and A. McMichael. 2005. Ecosystems and human wellbeing: Health synthesis. Geneva: World Health Organisation (WHO).

Fernandes, J.A., S. Kay, M.A. Hossain, M. Ahmed, W.W. Cheung, A.N. Lazar, and M. Barange. 2016. Projecting marine fish production and catch potential in Bangladesh in the 21st century under long-term environmental change and management scenarios. ICES Journal of Marine Science: Journal du Conseil 73 (5): 1357-1369.

Khan, A.E., P.F. Scheelbeek, A.B. Shilpi, Q. Chan, S.K. Mojumder, A. Rahman, A. Haines, and P. Vineis. 2014. Salinity in drinking water and the risk of (pre)eclampsia and gestational hypertension in coastal Bangladesh: A casecontrol study. PLoS One 9 (9): e108715. https://doi.org/10.1371/journal. pone. 0108715 .

MEA. 2003. Ecosystems and human well-being: A framework for assessment. A report of the conceptual framework Working Group of the Millennium Ecosystem Assessment. Washington, DC: Island Press. http://pdf.wri.org/ ecosystems_human_wellbeing.pdf. Accessed 01 Aug 2016.

NIPORT, Mitra and Associates, and ICF International. 2013. Bangladesh Demographic and Health Survey 2011. Dhaka/Rockville: National Institute of Population Research and Training (NIPORT), Mitra and Associates \& ICF International.

- 2016. Bangladesh Demographic and Health Survey 2014. Dhaka/ Rockville: National Institute of Population Research and Training (NIPORT), Mitra and Associates, and ICF International.

Rasheed, S., S. Jahan, T. Sharmin, S. Hoque, M.A. Khanam, M.A. Land, M. Iqbal, S.M. Hanifi, F. Khatun, A.K. Siddique, and A. Bhuiya. 2014. How much salt do adults consume in climate vulnerable coastal Bangladesh? BMC Public Health 14 (584). https://doi.org/10.1186/1471-2458-14-584.

Shamsudduha, M. 2013. Groundwater-fed irrigation and drinking water supply in Bangladesh: Challenges and opportunities. In Adaptation to the impact of climate change on socio-economic conditions of Bangladesh, ed. A. Zahid, M.Q. Hassan, R. Islam, and Q.A. Samad, 150-169. Dhaka: Alumni Association of German Universities in Bangladesh, German Academic Exchange Service (DAAD).

Talukder, M.R.R., S. Rutherford, D. Phung, M.Z. Islam, and C. Chu. 2016. The effect of drinking water salinity on blood pressure in young adults of coastal Bangladesh. Environmental Pollution 214: 248-254. https://doi. org/10.1016/j.envpol.2016.03.074. 
UNICEF. 2012. Nutrition Glossary: A resource for communicators. New York: United Nations Children's Fund (UNICEF). https://www.unicef.org/lac/ Nutrition_Glossary_(3).pdf. Accessed 7 June 2017.

WHF. 2017. Hypertension: Hypertension and cardiovascular disease. World Heart Foundation (WHF). http://www.world-heart-federation.org/cardiovascularhealth/cardiovascular-disease-risk-factors/hypertension. Accessed 7 Feb 2017. WHO. 2007. WHO child growth standards: Head circumference-for-age, arm circumference-for-age, triceps skinfold-for-age and subscapular skinfold-for-age: Methods and development. WHO child growth standards. Geneva: Multicentre Growth Reference Study Group, World Health Organization (WHO). http://www.who.int/childgrowth/publications/technical_report_2/en/. Accessed 1 Aug 2016.

2012. Guideline: Sodium intake for adults and children. Geneva: World Health Organization (WHO). http://www.who.int/nutrition/publications/ guidelines/sodium_intake_printversion.pdf. Accessed 1 Aug 2016.

Open Access This chapter is licensed under the terms of the Creative Commons Attribution 4.0 International License (http://creativecommons.org/licenses/ by/4.0/), which permits use, sharing, adaptation, distribution and reproduction in any medium or format, as long as you give appropriate credit to the original author(s) and the source, provide a link to the Creative Commons license and indicate if changes were made.

The images or other third party material in this chapter are included in the chapter's Creative Commons license, unless indicated otherwise in a credit line to the material. If material is not included in the chapter's Creative Commons license and your intended use is not permitted by statutory regulation or exceeds the permitted use, you will need to obtain permission directly from the copyright holder.

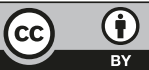

